\title{
As bordadeiras de Ibitinga: trabalho a domicílio e prática sindical ${ }^{*}$
}

\author{
Marcia de Paula Leite
}

\begin{abstract}
Resumo
Este texto analisa a história das trabalhadoras do bordado de Ibitinga, cidade do interior do estado de São Paulo conhecida pela beleza de seus produtos, especialmente os da linha de cama $e$ mesa. A partir de uma visão histórica, ele recupera a disseminação da indústria da confecção e do bordado na cidade, destacando o papel do sindicato na luta pela melhoria das condições de trabalho $e$, notadamente, pelo registro das trabalhadoras. $\mathrm{O}$ estudo enfatiza a importância dessas lutas na diminuição do trabalho a domicílio, bem como para a legalização das indústrias, a qual esteve na raiz do crescimento do setor nos últimos anos.
\end{abstract}

Palavras-chave: Sindicato, Trabalho a Domicílio, Bordadeiras, Trabalho Registrado.

\footnotetext{
* Recebido para publicação em outubro de 2007, aceito em fevereiro de 2008 Este trabalho é o resultado de uma pesquisa realizada para a OIT/Brasil nos anos de 2005 e 2006. Uma versão sintetizada dele foi apresentada no XXX Encontro Anual da ANPOCS, realizado em Caxambu 24-28 de Outubro de 2006, com o nome "As bordadeiras de Ibitinga: uma história de lutas que transformou a atividade na cidade". Agradeço à OIT/Brasil pela autorização para difundi-lo.

** Professora do Departamento de Ciências Sociais na Educação, Faculdade de Educação/Unicamp.mpleite@uol.com.br
}

cadernos pagu (32), janeiro-junho de 2009:183-214. 
As bordadeiras de Ibitinga: trabalho a domicílio e prática sindical

The Women Embroiderers from Ibitinga: Homework and Union Practices

\begin{abstract}
This paper analyses the history of women embroiderers from Ibitinga, a small town in the state of São Paulo, which is known by the beauty of its needlework. It recreates, from a historical perspective, the diffusion of the embroidery industry in the town, emphasizing the struggle of the worker's union to improve labor conditions and register workers at the Ministry of Labor. The study emphasizes the importance of worker's organization to decrease homework, as well as to legalize the industries, a process that lies at the roots of its vigorous growth during recent years.
\end{abstract}

Key Words: Union, Homework, Embroiderers, Legalized Work. 
Marcia de Paula Leite

\section{Introdução}

Até o final dos anos 1980, os trabalhadores do bordado e de confecção de Ibitinga viviam uma realidade bastante difícil: dispersos em pequenas empresas e, sobretudo, no trabalho a domicílio, não dispunham de contrato de trabalho; ganhavam, por peça, quantias insuficientes para a garantia de seu sustento; chegavam a trabalhar até doze horas por dia; apresentavam altos índices de doenças profissionais; possuíam um trabalho sazonal que em alguns períodos do ano lhes deixava sem remuneração $e$ eram compostos por uma maioria de mulheres e uma significativa presença de menores.

A criação de uma Associação Profissional dos Empregados em Empresas de Artesanatos em Geral de Ibitinga, em 1987, a partir de uma pesquisa sobre a categoria, desenvolvida por quatro estudantes (duas das quais eram também bordadeiras em Ibitinga) do Departamento de Comunicação Social da Universidade de Bauru (Bufelli et alii, 1987) consistiu no primeiro passo do processo de organização da categoria. Transformando-se rapidamente no Sindicato dos Bordadores de Ibitinga, a entidade protagonizou uma história de lutas que colaborou para mudar a situação dos trabalhadores, sobretudo trabalhadoras ${ }^{1}$, da confecção e do bordado, bem como para redefinir a estratégia das empresas, num processo que tornou a região um dos pólos industriais de produtos de cama, mesa e banho mais importantes do estado e do país. ${ }^{2}$

É a esse movimento que este texto se dedica, buscando desvendar a história social de uma categoria que, embora tenha colaborado para dar um outro perfil à indústria de confecção da região, é ainda pouco conhecida. Essa história será contada tendo

1 Tendo em vista a expressiva maioria de mulheres na categoria, usaremos sempre os termos no feminino para nos referir ao conjunto: bordadeiras, trabalhadoras etc.

2 Atualmente Ibitinga detém $29 \%$ das empresas do segmento de produtos têxteis para o lar no país. 
As bordadeiras de Ibitinga: trabalho a domicílio e prática sindical

como eixo a dimensão de gênero, tendo em vista a grande maioria de mulheres que compõe a categoria e o papel central que elas exerceram (e continuam a exercer) nos acontecimentos.

A pesquisa foi realizada a partir de entrevistas com a liderança sindical (a presidente e a tesoureira do sindicato), visitas a duas fábricas e a uma empresa terceirizada, entrevistas com dois gerentes de empresa, com dez operários (homens e mulheres), quatro trabalhadoras a domicílio, o presidente do sindicato patronal e o prefeito da cidade. Foram também recolhidos documentos dos sindicatos de trabalhadores e das indústrias, bem como reportagens da imprensa local.

\section{Ibitinga: da agropecuária ao bordado}

Situada no centro do estado de São Paulo, Ibitinga se dedicou desde seus primórdios à agricultura do café, a qual, após um período inicial de crescimento, entrou numa fase de estagnação com a crise dos anos 1930. É nesse contexto que o bordado foi introduzido na cidade por uma senhora de origem portuguesa, que começou a bordar em sua casa, a partir de 1945. Pouco a pouco, a arte de bordar foi se difundindo entre as mulheres.

A atividade do bordado assumiu, portanto, desde o início, várias características que marcam a divisão sexual do trabalho, já tão analisadas pela bibliografia dedicada ao tema: trabalho executado especialmente no âmbito doméstico, entremeando-se com as atividades de cuidado da casa $e$ dos filhos - entendidas como de responsabilidade feminina - e considerado como complementar em relação ao masculino, mesmo quando se configura como a principal atividade econômica do núcleo familiar (Abramo, 1998 e 2007; Abreu, 1986; Abreu e Sorj, 1994; Araújo, 2004; Leite, 2004; Maruani e Hirata, 2003).

Em 1950, surgiu a primeira máquina de bordado industrial na cidade, a partir de uma adaptação realizada na máquina de costura da Singer; com ela, iniciou-se a indústria do bordado em 
Ibitinga. Conforme explicitam Bufelli et alii (1987), com o início da produção industrial, o bordado começou a ser produzido em série, passando a dividir-se em várias fases, desenvolvidas por diferentes pessoas: o corte, o risco, o bordado propriamente dito, o arremate, a costura e a lavanderia. A divisão do trabalho, aliada ao rápido aumento da produção industrial, começou a trazer também o homem para a atividade: a confecção e o bordado assumiam o status de principal atividade econômica local $e$ Ibitinga iniciava um rápido desenvolvimento econômico.

Esse processo dá um novo salto em 1973, com o início do funcionamento da escola de bordado da Singer, que passou a ensinar a atividade gratuitamente, e, especialmente, com a realização da I Feira do Bordado de Ibitinga, no ano seguinte. A feira foi visitada por oito mil pessoas e contou com onze firmas expositoras de bordado (Sawaia, 1979:114). O acontecimento deixou os expositores praticamente sem estoques e teve um efeito dinamizador para a economia da cidade. De acordo com Bufelli et alli (1987:19), o salário médio familiar mais que duplicou e foi a partir desse momento que a entrada do homem na atividade se disseminou de forma mais evidente.

Valeria fazer uma reflexão aqui sobre esse movimento de inserção da força de trabalho masculina no bordado. De acordo com Sawaia (1979), a partir de 1974, começou a ser desenvolvida uma campanha destinada a atrair a força de trabalho masculina para a atividade, que buscou valorizar o bordado enquanto atividade profissional, desvinculando-a de sua tradicional relação com o trabalho feminino. Essa campanha, organizada pela prefeitura, pelo Banco do Brasil e outras figuras públicas locais, foi liderada especialmente pela rádio local, que passou a transmitir comentários nesse sentido (Sawaia, 1979:114-123).

Esse movimento, acompanhado de uma pressão sobre o revendedor da Singer para que abrisse as portas da escola aos homens, visou resolver o problema de carência de mão-de-obra disponível para o bordado à medida que o negócio se expandia, buscando reverter a relação das bordadeiras com o nascente 
As bordadeiras de Ibitinga: trabalho a domicílio e prática sindical

capital industrial da cidade. Essa situação é claramente evidenciada na pesquisa de Sawaia (1979:118-119) a partir de entrevistas realizadas com proprietárias de salão, nas quais elas elucidam que as mulheres são insuficientes para atender a demanda de produção, ou queixam-se de suas exigências.

O sucesso da I Feira foi se repetindo nos anos seguintes ${ }^{3}$ em que as exposições continuaram a dinamizar a atividade $e^{4}$, aumentando continuamente o número de trabalhadores com elas envolvidos e tornando-as cada vez mais conhecidas em nível nacional. De acordo com Sawaia (1979:99), já em 1978, de uma população provável de 40 mil habitantes, a cidade possuía entre 25 a 30 mil pessoas envolvidas com a atividade do bordado.

É importante ressaltar que, por ser uma atividade tradicionalmente feminina, na medida em que o bordado foi conquistando um papel destacado na economia local, ele foi também promovendo o trabalho feminino à condição de principal agente produtivo. ${ }^{5}$ Esse fato não foi suficiente, contudo, para modificar significativamente os tradicionais papéis de gênero, anteriormente referidos, nem as relações sociais de gênero que sobre eles se erigem. Com efeito, embora a mulher tivesse ingressado na atividade há mais tempo que o homem, dominando a técnica do bordado e ganhando em geral mais que o marido, as representações sobre os papéis de gênero não se alteraram (Sawaia, 1979:134).

\footnotetext{
3 A feira anual foi oficializada por intermédio de legislação promulgada a 30/07/1974 que a tornou uma atividade regular da Prefeitura Municipal.

4 Só para se ter uma idéia da importância desse evento, destaque-se que a feira realizada em 1976 foi visitada por 25.579 mil pessoas, mais de três vezes do que a primeira.

5 Observe-se que o papel da mulher continuou central na atividade, mesmo com a progressiva entrada do homem, já que o expertise do bordado continuou concentrado em mãos femininas (Sawaia, 1979:98).
} 
Marcia de Paula Leite

\section{As características do trabalho no final dos anos 1980}

O desenvolvimento do setor do bordado não redundou, tampouco, em melhorias significativas das condições de trabalho no setor. Até 1987, as empresas empregavam um pequeno número de trabalhadoras, baseando grande parte da sua produção no trabalho subcontratado realizado em salões de bordado ou a domicílio; as trabalhadoras eram pagas por peça $e$ poucas possuíam registro em carteira.

Os dados colhidos, pela pesquisa levada a cabo por Bufelli et alii (1987), entre 1.045 bordadeiras revelavam uma categoria majoritariamente feminina, bastante informalizada, mal paga, jovem, com baixa escolaridade, e sem condições de continuar os estudos devido à precariedade das condições de trabalho e às longas jornadas.

No que respeita ao gênero, $89,6 \%$ da amostra era constituída de mulheres, enquanto os homens correspondiam a apenas $9,9 \%$. No que se refere à formalização do trabalho, apenas 88 (8,4\%) eram registradas como autônomas e 141 (13,5\%) em carteira de trabalho, sendo a maioria $(77,5 \%)$ constituída de trabalhadoras sem registro e, portanto, sem acesso aos direitos trabalhistas. Também no que diz respeito aos salários, os dados descortinavam uma realidade bastante dura: $92,4 \%$ das trabalhadoras ganhavam até 3 salários mínimos, sendo que 43,3\% do total recebia até 1 salário.

Os dados relativos à idade identificavam uma força de trabalho jovem, $7,7 \%$ da qual configurava trabalho infantil (entre 10 a 15 anos de idade). Quando considerados em relação com a escolaridade, os dados revelavam uma realidade ainda menos alentadora: embora uma grande porcentagem do total fosse jovem (48\% com até 22 anos de idade), $72 \%$ possuísse a escolaridade básica incompleta ${ }^{6}$ e apenas $22 \%$ ainda estudava. A pesquisa

6 Estes $72 \%$ se encontravam assim distribuídos: 2,2\% eram analfabetas; $48,2 \%$ possuíam até a $4^{\mathrm{a}}$ série; e $21,6 \%$ se encontravam no nível de $5^{\mathrm{a}}$ a $8^{\mathrm{a}}$ séries incompleto. 
As bordadeiras de Ibitinga: trabalho a domicílio e prática sindical

evidenciou também uma grave evasão nas escolas de Ibitinga ${ }^{7}$, imputada pelas pesquisadoras ao fato de que

grande parte das crianças abandona a escola para bordar ou exercer alguma atividade relacionada ao bordado, especialmente na época das Feiras, quando as fábricas necessitam de mais mão-de-obra (Bufelli et alii, 1987:23).

Além disso, as condições de trabalho das bordadeiras nas fábricas e salões eram extremamente duras. Alguns depoimentos e documentos recolhidos durante a pesquisa são ilustrativos a respeito. A tesoureira do sindicato, por exemplo, lembra que quando começou a trabalhar em um salão de bordado, aos nove anos, era trancada juntamente com mais três ou quatro jovens em uma sala para que não abandonassem o trabalho durante a jornada. O pagamento consistia em um pedaço de bolo e uma ajuda insignificante em dinheiro. Em matéria publicada em 1989, na primeira edição do Nossa Luta, órgão informativo do sindicato, o jornal denunciava que em muitas empresas havia "encarregadas de salão", que ficavam

posicionadas em frente às máquinas de bordar, advertindo as bordadeiras a cada simples virada de cabeça. Não pode haver paradas nem para relaxar a coluna.... Quando vão ao banheiro, existe um tempo estipulado que, caso ultrapassado, é descontado no salário. Os trabalhadores devem ocupar suas máquinas ou funções 15 minutos antes do horário, para quando soar o sinal não haver perda de tempo (Nossa Luta (1), novembro de 1989).

7 O estudo registrou que de 5.049 alunos que haviam ingressado no $2^{\circ}$ Grau em 1983, apenas 567 (aproximadamente 11\%) havia concluído o curso em 1985 (Bufelli, 1987:22). 
A publicação denunciava também as más condições de saúde das bordadeiras provocadas pelas duras condições de trabalho.

\section{A formação da Associação e do Sindicato}

O estudo desenvolvido por Bufelli et alii. (1987) adotou a metodologia da pesquisa-ação, buscando instrumentalizar as trabalhadoras que participaram da pesquisa a assumir sua experiência cotidiana de vida e de trabalho como fonte de ação transformadora. Baseadas nessa compreensão, as pesquisadoras iniciaram um processo de reflexão sobre a realidade revelada pela pesquisa com as bordadeiras implicadas na investigação. A partir da terceira reunião, o grupo começou a discutir a possibilidade de criação de uma associação e em novembro de 1987 foi oficialmente criada a Associação Profissional dos Empregados em Empresas de Artesanatos em Geral de Ibitinga, tendo como meta prioritária sua breve transformação em sindicato.

A carta sindical foi entregue em agosto de 1988, quando foi fundada a entidade e tomou posse a primeira diretoria do Sindicato dos Empregados em Empresas de Artesanatos em Geral de Ibitinga, que mudou o nome alguns anos mais tarde para Sindicato dos Trabalhadores nas Indústrias de Confecção $e$ Bordado de Ibitinga e Região. Inicialmente, foram registrados, associação e sindicato, como "dos Empregados em Empresas de Artesanato em Geral", porque à época a atividade do bordado não constava da $\mathrm{CBO}$, não sendo considerada, portanto, uma profissão. O Sindicato elegeu como seu primeiro desafio a luta pelo reconhecimento da profissão e, portanto, pela profissionalização das trabalhadoras do bordado por meio da regulamentação da profissão no Ministério do Trabalho, visando, a partir daí, poder iniciar a luta pelo registro em carteira da categoria.

Cabe aqui uma reflexão sobre a ênfase que o sindicato conferiu à formalização do trabalho, buscando garantir os direitos 
As bordadeiras de Ibitinga: trabalho a domicílio e prática sindical

trabalhistas das trabalhadoras a domicílio, bem como o combate a esse tipo de trabalho, já que a garantia desses direitos foi o principal fator a limitar a sua ocorrência. ${ }^{8} \mathrm{O}$ fato de a associação $e$ o sindicato terem sido fundados por mulheres que vivenciavam cotidianamente os constrangimentos do trabalho a domicílio teve uma enorme importância para a estratégia sindical ter-se centrado nessa luta. Com efeito, ao contrário de vários sindicatos de categorias essencialmente femininas que contam com uma diretoria com grande presença masculina (quando não majoritária) $-e$ as reivindicações femininas acabam não sendo inseridas com a devida ênfase na mesa de negociações - o Sindicato das Bordadeiras de Ibitinga foi, desde o início, uma entidade formada por mulheres e voltada a seus interesses. Vale destacar também que embora as diretorias busquem um equilíbrio entre os dois sexos, as mulheres têm sistematicamente ocupado os cargos mais importantes (presidente, tesoureira, secretária), desempenhando papel fundamental na definição das estratégias da entidade (O Comércio, 12/03/1988).

\section{As lutas sindicais e as mudanças no perfil industrial}

O não reconhecimento da profissão pelo Ministério do Trabalho tornava difícil a formalização do trabalho, o que levou o sindicato a buscar o registro das trabalhadoras por meio de sentença judicial. Para isso, a entidade levou a frente um incessante trabalho visando provar na Justiça do Trabalho que as bordadeiras tinham jornada de trabalho estabelecida, que eram subordinadas, que recebiam por peça e que não conseguiam ganhar nem mesmo o salário mínimo.

A primeira conquista importante consistiu na regulamentação da profissão de bordadeira e o estabelecimento

8 De fato, sendo obrigadas a registrar, as empresas tendiam a preferir o trabalho assalariado exercido na própria fábrica ou salão, na medida em que com essa obrigatoriedade, elas perdiam a grande vantagem do trabalho a domicílio, que era o não pagamento dos direitos trabalhistas. 
do piso da categoria (em 1990). Mas se esse passo era fundamental, ele não garantia a regularização dos contratos de trabalho. Dessa forma, o centro da luta sindical continuou sendo o registro em carteira das bordadeiras, fossem elas empregadas de empresa, de salão de bordado, ou trabalhadoras a domicílio. No que se refere ao trabalho executado nas empresas, o sindicato denunciava as estratégias utilizadas como forma de evitar o contrato:

Em Ibitinga, costuma-se não registrar o empregado imediatamente à sua admissão. É hábito prometer o registro dentro de um determinado tempo, só que esse tempo é interminável... Há empregados que trabalham anos esperando registro e no fim são despedidos, recebendo o aviso de que não têm direito a nada $(O$ Comércio de Ibitinga, 08/05/1993:5).

No que respeita às trabalhadoras a domicílio ou nos salões de bordado, a estratégia baseou-se na caracterização da sua relação de trabalho como uma relação de emprego que devia, portanto, ser regida pelo contrato de trabalho. Essa posição provinha da interpretação sobre a legislação, que considera não haver distinção entre o trabalho efetuado no estabelecimento do empregador e o desenvolvido no domićlio do empregado, conforme explicitam as palavras de uma diretora do sindicato:

A legislação é bem clara: não há distinção entre o trabalho executado no estabelecimento do empregador e aquele realizado no domicílio do empregado. Com base no artigo $6^{\circ}$ da Consolidação das Leis do Trabalho (CLT), será considerado empregado o trabalhador que prestar serviço em seu próprio domicílio, desde que esteja caracterizada a relação de emprego. A relação de emprego se caracteriza, portanto, sempre que alguém estiver prestando serviços a outrem sob dependência e mediante pagamentos de salário. 
As bordadeiras de Ibitinga: trabalho a domicílio e prática sindical

O trabalhador (...) do bordado (...) se submete a uma direção, pelo empregador, (...) ou seja, a empresa intervém nas atividades, através da expectativa permanente, fiscalização... e imposições de preço. Portanto, havendo a completa relação empregatícia, deve haver também o contrato de Trabalho e Previdência Social, resultando na garantia de todos os Direitos... (O Comércio de Ibitinga, 08/05/1993:5).

Esse tipo de estratégia levou o sindicato a desenvolver uma forte relação com as trabalhadoras a domicilio e colaborou para a expansão do bordado na cidade, ao forçar as empresas a se organizar e regularizar sua atividade, uma vez que, para registrar as trabalhadoras, necessitavam estar registradas como empresas, com situação regularizada na Receita Federal.

Os dados disponíveis indicam que o crescimento da atividade nos anos que se seguiram à fundação do sindicato coincide com a regularização das empresas. De fato, se a pesquisa realizada em 1987 por Bufelli et alii, encontrara que as trabalhadoras do bordado representavam $25 \%$ da população local, em 1991, a Folha de São Paulo informava que cerca de $85 \%$ das famílias da cidade já se dedicavam à fabricação do bordado, que respondia por $80 \%$ da economia local (Folha de São Paulo, SP Nordeste, $10^{\circ}$ Caderno, 13/07/1991:1). Outra matéria da Folha de São Paulo, publicada em maio de 1991 identificava por volta de 1.300 empresas do setor em Ibitinga, das quais metade possuía registro. A porcentagem de trabalhadoras com carteira de trabalho assinada, entretanto, parecia não crescer proporcionalmente: de acordo com declaração da presidente do sindicato, na mesma matéria, das cerca de 10.000 empregadas do bordado, apenas 1,2 mil $(12 \%)$ tinham registro em carteira.

A estratégia sindical consistiu em fazer constar sistematicamente da pauta de reivindicações a demanda de registro de todas as trabalhadoras do bordado, além de denunciar constantemente a prática empresarial de não regulamentação de seus empregados. Ademais, o sindicato promoveu e esteve 
presente em inúmeros eventos destinados à discussão do trabalho a domicílio, como forma de conscientizar as trabalhadoras $e$ alertar as empresas e os poderes públicos sobre a situação por elas vivida.

Outra estratégia importante foi entrar em maio de 1991 com várias ações na Justiça do Trabalho, pedindo reposição das perdas havidas com a implantação do Plano Collor no ano anterior. A intenção foi utilizar essas ações para provar na Justiça a existência do trabalho sem registro, como atestam as palavras da tesoureira do sindicato:

Nós mandamos o processo em cima das empresas, pedindo para que eles pagassem aquela diferença para 0 trabalhador. Mas que trabalhador, se elas não tinham trabalhador? Daí foi a hora de a gente ficar frente a frente com os empregadores na Justiça e eles falavam: 'Eu não devo essa diferença por que eu não tenho trabalhador'. E essa foi a hora de a gente desmascará-los: 'Mas como que eles têm todos aqueles produtos na empresa se eles não têm trabalhador; quem produz pra ele?' Com isso a gente foi provando que eles tinham um monte de trabalhadoras, só que elas não eram registradas. Nós ganhamos o processo e conseguimos aumentar muito o trabalho registrado porque a Justiça foi intimando os empregadores a pagar as pessoas e automaticamente eles tinham que reconhecer aquela pessoa como funcionária.

O mesmo tipo de estratégia foi utilizado na luta contra a terceirização, conforme atestam as palavras da presidente:

Tinha muita obra terceirizada; a empresa repassava para uma pessoa e essa pessoa repassava para a cidade inteira... Daí, nós provamos que a empresa principal, a tomadora de serviço, era a empresa X; porque como vai bordar, costurar, tem lá a etiqueta do fabricante? Então a gente levava aquele bolo de etiquetas para provar... a empresa tomadora 
As bordadeiras de Ibitinga: trabalho a domicílio e prática sindical

de serviço é essa aqui. Daí começamos a ganhar as ações contra as empresas.

Essa ação sindical levou as empresas maiores a exigir uma organização dos terceirizados no sentido de que eles também fizessem o registro como empresa $e$ que regularizassem as trabalhadoras pagando os direitos trabalhistas. Esse tipo de ação limitou a precarização do trabalho nas terceirizadas, assim como a utilização do trabalho a domicílio, ao contrário do que vem acontecendo em muitas outras cidades, como por exemplo, São Paulo e Campinas (Amorim e Araújo, 2002; Leite, 2004).

Vale destacar que esse processo foi também de enorme importância no sentido de fortalecer a auto-estima das trabalhadoras, favorecendo a tomada de consciência de que elas tinham direitos relacionados ao trabalho $e$, inclusive, que elas podiam reivindicá-los, muitas vezes contrariamente até à opinião de seus maridos, temerosos das conseqüencias da denúncia. Conforme explicita a atual presidente do sindicato:

O sindicato tinha que ficar indo nas casas por que senão ela desistia. E muitas vezes ela aparecia toda roxa, machucada porque antes de sair de casa ela apanhava do marido porque ia denunciar.

Esse processo teve outra conseqüencia de grande importância para as bordadeiras, que foi a luta, vitoriosa, liderada pelo sindicato pela abertura de uma delegacia da mulher na cidade, o que significou mais um passo importante no sentido da valorização e independização da mulher.

Em agosto de 1991, a Secretaria Estadual da Mulher da Confederação Geral dos Trabalhadores (CGT) promoveu em Ibitinga um seminário sobre trabalhadores a domicílio, com a ativa participação do Sindicato, conseguindo mobilizar o apoio do poder público, assim como de representantes dos empresários. Referindo-se à situação das trabalhadoras do bordado, a presidente do sindicato declarou na ocasião: 
Marcia de Paula Leite

Quando há um abalo na economia, a primeira mercadoria a cair é o trabalhador, pois não há estabilidade no emprego e a cada crise aumenta o número de empresas clandestinas (O Comércio, 31/08/1991).

Também o representante da Prefeitura Municipal se manifestou sobre o tema, ressaltando que a cidade vivia

o modelo neocapitalista, com um atraso técnico espantoso $e$, diante desse quadro a relação patrão-empregado não poderia ser diferente. Vivemos uma bagunça organizativa [alertou] (O Comércio, 31/08/1991).

O seminário foi um passo importante para a conscientização das trabalhadoras, de empregadores e da prefeitura sobre a gravidade da situação e permitiu o consenso sobre a necessidade de unir poder público e sindicatos para discutir a situação do município. A importância dessa união de esforços merece destaque, tendo em vista que a luta adquiria muito mais força $e$ visibilidade com a entrada do poder público.

Outro momento importante foi a Convenção Coletiva assinada em abril de 1992, na qual o sindicato conquistou o poder de verificar se as cláusulas aprovadas estavam sendo cumpridas pelas empresas. Ela permitiu ao sindicato iniciar um processo de fiscalização nas empresas, cuja legitimidade foi explicitada em nota enviada à imprensa. Na nota, o sindicato esclarecia que, face aos acontecimentos relativos à Convenção Coletiva, havia se dirigido ao Ministro do TST para expor as condições trabalhistas em Ibitinga e que o Ministro pedira que a entidade fizesse um relatório sobre a realidade trabalhista local para ser encaminhado ao Ministro do Trabalho e ao TST (O Comércio, 11/07/1992). No início do ano seguinte, o sindicato ameaçava o empresariado de dirigir-se novamente ao Ministério do Trabalho para pedir uma devassa fiscal trabalhista em Ibitinga (A Comarca Regional de Monte Alto, de 7 a 17/02/1993). 
As bordadeiras de Ibitinga: trabalho a domicílio e prática sindical

Essas atividades redundaram na consolidação do poder de fiscalização do sindicato a partir da cláusula assinada na Convenção Coletiva de Trabalho de maio daquele ano, que consistiu no livre acesso dos dirigentes sindicais aos locais de trabalho para vistoria do fiel cumprimento do acordo firmado entre as partes. Por meio dessa conquista, o sindicato adquiriu capacidade de interferir na relação de trabalho, já que ela lhe facultava detectar as irregularidades e passar as informações ao Ministério do Trabalho que, então, autuava as empresas. De acordo com a tesoureira do sindicato, isso permitiu o registro de um número significativo de trabalhadoras, coisa que o Ministério não teria conseguido sozinho.

Nesse mesmo acordo, o sindicato conquistou o direito de representação de todas as trabalhadoras do bordado, inclusive aquelas que executavam suas funções na residência; adicional noturno de 30\%; quinze minutos de intervalo sempre que o trabalho ultrapassasse quatro horas de atividades ininterruptas, sem desconto em salário ou necessidade de compensação; $100 \%$ de hora extra; e 180 dias de beneficiamento previdenciário em casos de acidente de trabalho.

Já no mês seguinte, a diretoria do sindicato anunciava que iniciaria "um trabalho de averiguação quanto ao cumprimento da Convenção Coletiva" e informava que sua realização se daria de duas formas: a partir da participação indireta das próprias trabalhadoras, por meio da denúncia das irregularidades ao sindicato; e com a realização de "um trabalho de vistoria nas empresas através de um membro da diretoria, baseado na cláusula $31^{a}$ da Convenção Coletiva para a verificação do devido cumprimento". Após a constatação das irregularidades, alertava o sindicato,

será encaminhado um pedido de fiscalização ao Ministério do Trabalho, que é o órgão competente para a autuação das empresas (...) e o sindicato vai requerer na Justiça (...), 
Marcia de Paula Leite

a multa constante na cláusula $43^{a}$ da Convenção Coletiva de Trabalho.

A nota terminava afirmando que esse trabalho consistia em mais uma tentativa do sindicato de conter a onda de irregularidades que havia tomado conta da cidade (O Comércio, 12/06/1993:4).

A partir desse trabalho, o sindicato conseguiu viabilizar uma fiscalização da Previdência Social na cidade durante a maior parte de 1993 e manteve o registro das bordadeiras como centro da luta sindical, com forte atenção dedicada às trabalhadoras a domicílio. Tal concentração de esforços fez com que o número de trabalhadoras com carteira assinada no município saltasse de 1.300 em janeiro de 1993 para 2.100 em janeiro de 1994, um aumento de quase $50 \%$. Animada com o resultado, a diretoria do sindicato lança em fevereiro de 1994 uma Campanha pelo Registro em Carteira, que contou com a palestra de um representante do Ministério do Trabalho. Na ocasião, o sindicato requisitou a continuação da fiscalização do INSS e estendeu a campanha para cidades vizinhas, recém incorporadas à base sindical (O Comércio, 29/01/1994).

A luta sindical fortaleceu-se significativamente com o lançamento da Campanha da Carteira Assinada pelo Ministério do Trabalho, na gestão do Ministro Barelli. A orientação do Ministério também veio ao encontro dos esforços do sindicato, com a criação da Portaria $\mathrm{n}^{\circ}$ 989, em agosto de 1994, a fim de tornar mais produtiva e eficaz a ação fiscal. De acordo com a Portaria, os sindicatos foram reconhecidos como "órgãos que devem colaborar com o poder público, acionando a fiscalização para que esta possa realizar com mais êxito sua tarefa". Esse trabalho dos sindicatos poderia ser feito, segundo a Portaria, "através de comunicação à Delegacia Regional do Trabalho, quando há existência ou indícios de fatos irregulares inerentes à Legislação Trabalhista". Ainda de acordo com a Portaria, após a denúncia, "as DRTs ficam obrigadas a fiscalizar e apurar imediatamente os fatos, dando ciência imediata do resultado da fiscalização ao 
As bordadeiras de Ibitinga: trabalho a domicílio e prática sindical

trabalhador, à entidade denunciante e à Secretaria do Trabalho" (O Comércio, 27/08/1994:4).

De fato, a Portaria incentivou o sindicato a agilizar o trabalho de visita às empresas, a fim de constatar o cumprimento da Convenção Coletiva de Trabalho assinada em abril de 1994. Conforme as palavras de uma das diretoras do sindicato:

As visitas têm como objetivo principal conscientizar $e$ orientar, buscando a regularização. Sendo assim, o Sindicato dos Trabalhadores do Bordado de Ibitinga espera contar com o bom senso da classe empresarial no desenvolvimento dos trabalhos; caso contrário usará das atribuições legais, conferidas pela Portaria 989 do Ministério do Trabalho e o Decreto-Lei 1197/94 do INSS para tomar as medidas cabíveis e administrativas para cada caso $(O$ Comércio, 27 de agosto de 1994: 4).

O avanço sindical já era evidente nesse momento, expressando-se inclusive na reação do empresariado. Para o presidente do Sindicato Empresarial (SINDICOBI - Sindicato das Indústrias e Comércio de Bordados de Ibitinga), a convenção entre os dois sindicatos estipulou normas que deveriam ser seguidas pelas empresas: "Se houver empresa em desacordo com essas normas, deverá ser notificada para correção", afirmou o presidente, completando, "o que é de direito, é de direito" $(O$ Comércio, 27/08/1994:4).

Esse período foi bastante benéfico para a indústria do bordado na cidade, que crescia e se regularizava, ao mesmo tempo em que criava melhores condições de trabalho para a categoria. A economia florescia e, ao contrário da maior parte das cidades do estado e do país, Ibitinga apresentava baixos índices de desemprego. A situação, entretanto, voltou a piorar com a crise que se irrompe a partir do Plano Real e das medidas de abertura econômica tomadas pelo Governo Federal. Conforme as palavras de uma das diretoras do sindicato: 
Em Ibitinga, a economia informal sempre teve um grande espaço, mas após o Plano Real atingiu um nível ainda maior. O número de trabalhadores contratados sem carteira assinada aumenta na mesma proporção das demissões, e é praticamente impossível fazer uma estimativa do número de pessoas envolvidas direta ou indiretamente com a economia informal (O Comércio, 02/09/1995:5).

Segundo entrevista fornecida pelo presidente do SINDICOBI, esse período foi muito difícil para a indústria em função da competição dos produtos internacionais, $e$ as empresas enveredaram por uma estratégia de competição por custos, buscando baixar o preço das mercadorias. Os efeitos danosos dessa política repercutiram tanto nas condições de trabalho da categoria, como na qualidade dos produtos.

O sindicato continuou seu trabalho de denúncia da irregularidade, alertando para a expansão do que denominou de os sem-carteira (O Comércio, 14/09/1996:2). Novamente, em 1997, voltava ao assunto, denunciando o crescimento da informalidade no país e, particularmente, em Ibitinga. Conforme as palavras de uma diretora:

Nos grandes centros, a informalidade acontece automaticamente. O trabalhador se vê desempregado $e$ obrigado a procurar novas fontes de renda e apela para o "negócio próprio". Em cidades menores, como é o caso de Ibitinga, a informalidade se transforma em irregularidade. Grande parte dos "informais" e "autônomos" ibitinguenses, na verdade, deveriam ter o registro em carteira e seus direitos trabalhistas reconhecidos. Mas muitos empresários insistem em não conhecer a realidade e partem para a irregularidade. Infelizmente, por força da necessidade, muitos trabalhadores se submetem a trabalhar de forma irregular... (O Comércio, 28/06/1997:2). 
As bordadeiras de Ibitinga: trabalho a domicílio e prática sindical

A partir de 1999, o Sindicato abraçou, com o apoio da CGT, o Programa Cidadania e Emprego do Governo Federal, promovendo a realização de cursos de formação profissional (Nossa Luta, dezembro de 1999) e formando até o final de 2002 mais de 3000 alunos em várias áreas (Nossa Luta, setembro de 2002).

Se o conjunto dessas práticas visava melhorar a condição de emprego da categoria, elas acabaram cumprindo também a função de pressionar as empresas a mudarem sua estratégia no sentido de buscar um caminho mais voltado para a qualidade dos produtos e a qualificação da força de trabalho $e$ menos assentado na competitividade por custo. Essa mudança de rota foi fundamental tanto para as trabalhadoras como para a própria indústria de Ibitinga, tendo em vista que logrou disseminar entre o empresariado uma consciência de que seus esforços deveriam se concentrar em investimento, tecnologia e melhoria da mão-deobra. O efeito dessa campanha sobre o empresariado pode ser percebido nas palavras de um dos gerentes entrevistados:

O empresariado de Ibitinga trabalhava totalmente errado; ele não registrava seus trabalhadores, não pagava os direitos. Quando surgiu o sindicato, a rejeição foi muito grande. Existia um monte de brigas judiciais; isso aí foi uma guerra. Quando surgiu o sindicato, nossa, o pessoal não podia nem ver a direção do sindicato. Mas com o tempo foi incutindo na cabeça do empresariado que isso era bom pra eles. Tanto é que hoje, o sindicato é super respeitado. O sindicato patronal e o dos empregados são muito unidos, falam a mesma língua.

O interessante a registrar é que esse movimento acabou se difundindo entre as empresas, alcançando o conjunto delas. Tanto as entrevistas realizadas no Sindicato das Bordadeiras, como as com os gerentes revelaram esse fato, destacando que as empresas que não acompanharam o processo acabaram quebrando. Como expressou um gerente: 
Os que foram se adaptando conseguiram ir pra frente $e$ muita gente que resistiu, resistiu, resistiu e acabou quebrando. Porque antigamente era só sonegação, né? Sonegação do funcionário, sonegação dos impostos e na hora da mudança, da readaptação, ele não entendeu tudo isso aí.

A luta do sindicato redundou, em abril de 2001, na conquista do registro em carteira por todos os

empregados que executem serviços na empresa (salão), ou fora "dele", com máquinas próprias ou de "terceiros", garantindo-lhes o salário e todos os benefícios adquiridos pela categoria (Convenção Coletiva dos Trabalhadores na Indústria de Confecções e do Bordado de Ibitinga e Região, abril de 2001).

Essa conquista representa um feito de enorme importância não só para o Sindicato local, mas para o movimento sindical brasileiro, tendo em vista que para tanto a entidade se baseou na própria legislação, abrindo um precedente que pode ser seguido por muitos outros sindicatos e categorias.

De acordo com a presidente do sindicato, graças a essa vitória, o sindicato tem conseguido regularizar a situação de muitas trabalhadoras a domicilio, as quais vêm diminuindo numericamente, bem como garantir o cumprimento dos direitos que essas trabalhadoras conquistaram, especialmente o piso salarial.

É nesse contexto que a diretoria que tomou posse em dezembro de 2006, já pôde juntar as conquistas do sindicato em um amplo leque de direitos, que incluem:

1) reconhecimento da profissão de bordadeira pelo Ministério do Trabalho, conquistado em 1990; 
As bordadeiras de Ibitinga: trabalho a domicílio e prática sindical

2) um dos maiores pisos salariais para as trabalhadoras da confecção e do bordado (que têm o mesmo piso) do estado de São Paulo (R $\$ 613,00) ;{ }^{9}$

3) direito de representar todas as trabalhadoras que trabalham nas empresas ou nos seus domicílios, conquistado em 1992;

4) garantia do registro em carteira de todas as empregadas que executem serviços na empresa (salão), ou fora 'dele', com máquinas próprias ou de 'terceiros', com direito a todos os benefícios adquiridos pela categoria, inclusive o piso salarial, conquistado em 2001;

5) acesso às empresas para verificação do cumprimento da Convenção Coletiva, conquistado em 1992;

6) $100 \%$ de hora extra, conquistado em 1992 ;

7) $30 \%$ de adicional noturno, conquistado em 1992;

8) 6 meses de estabilidade de auxílio doença, conquistado em 1992.

9) promoção de igualdade, conquistado em $2006 .{ }^{10}$

Conforme já explicitado, essa história de lutas foi importante não só para a garantia de melhores condições de vida e de trabalho das trabalhadoras, mas para a regulamentação das próprias empresas, que tiveram que se organizar para acompanhar as reivindicações do sindicato. Nesse sentido, ela acabou favorecendo o fortalecimento de um modelo de

9 Para o Sindicato das Costureiras de São Paulo e Osasco o piso era de $\mathrm{R} \$$ 502,00 para a maior parte das costureiras, alcançando o valor de 659,00 para as qualificadas; o resto das cidades do estado seguia o piso conquistado pela Federação que era de $\mathrm{R} \$ 544,00$. Destaque-se ainda que o salário mínimo real em Ibitinga estava bem acima do piso, por volta de $\mathrm{R} \$ 750,00$. Segundo a presidente do sindicato, hoje (2006) ninguém trabalha por menos que esse valor.

${ }^{10}$ A cláusula conquistada reza que os sindicatos de empregados e empregadores se comprometem a promover políticas de igualdade e tratamento, através de programas educativos dirigidos às empresas, com o fim de evitar práticas discriminatórias, cabendo aos sindicatos propor, monitorar e realizar os referidos programas (Convenção Coletiva de Trabalho, 2006:9). 
Marcia de Paula Leite

competitividade hoje dominante na cidade, assentado na qualidade dos produtos e da força de trabalho.

Esse caminho consolidou-se nos últimos anos com a implantação do Projeto do APL (Arranjos Produtivos Locais) ${ }^{11} e$ um conjunto de iniciativas que vêm sendo tomadas pelos empresários do setor, dando um novo perfil às empresas e à cidade.

\section{A implantação do APL}

O APL Ibitinga é um projeto do Governo Estadual, SEBRAE e FIESP, que conta também com a promoção do SINDICOBI. A iniciativa de sua implementação foi da FIESP, que elegeu 10 arranjos produtivos no estado de São Paulo para investir, juntamente com o SEBRAE. Segundo o presidente do SINDICOBI, a reação empresarial foi um pouco reticente no início, tanto que o primeiro grupo contou com apenas 19 empresas. Conforme o programa foi caminhando e os resultados se tornaram evidentes, entretanto, os empresários foram abraçando a idéia; o segundo grupo reuniu 36 empresas e várias já estavam inscritas para o grupo 3, implantado em junho de 2007.

\footnotetext{
${ }^{11}$ Os Arranjos Produtivos Locais constituem aglomerações de pequenas e médias empresas localizadas em um mesmo território, que apresentam especializações produtivas e mantêm algum vínculo de articulação, interação, cooperação e aprendizagem entre si e com outros atores locais como governo, associações empresariais, instituições de crédito, ensino e pesquisa. Tendo como elemento central a confiança mútua dos empreendedores entre si, assim como nas instituições públicas, o APL busca a convergência em termos de expectativas de desenvolvimento e garante compromissos de investimentos no próprio território (Informativo SINDICOBI, julho de 2005:3). O APL é uma criação desta gestão do Governo Federal e hoje praticamente todos os ministérios possuem uma linha de apoio a APLs. Foi também criado um grupo de trabalho permanente interministerial (GTP-APL) visando aumentar a coordenação dos vários ministérios e agências não-governamentais envolvidos na sua promoção. A atualização do levantamento dos APLs no país, realizada em 2005, identificou 955 arranjos.
} 
As bordadeiras de Ibitinga: trabalho a domicílio e prática sindical

O projeto iniciou-se no começo de 2003 e em setembro desse ano formava-se o primeiro grupo. O objetivo dos grupos é promover informações, diagnósticos, treinamentos, palestras, workshops, consultorias e planejamento estratégico das empresas, de forma a permitir que a estratégia empresarial amplie seus prazos e se iniciem estratégias de crescimento e desenvolvimento. A lógica dos APLs é que as novas oportunidades identificadas pelas empresas sejam compartilhadas pelo grupo todo por meio de discussões e sugestões que promovam a realização de parcerias e que as empresas vejam seus concorrentes como um parceiro na construção da eficiência coletiva (Informativo SINDICOBI, agosto de 2005:3).

A primeira fase do projeto terminou em setembro de $2004 e$ em dezembro desse mesmo ano já se iniciava a segunda fase, com a formação do segundo grupo. De acordo com um gerente da FIESP, "os empresários do setor do bordado de Ibitinga que participaram da implantação do Projeto tiveram em média um aumento de $30 \%$ em sua produção" (Informativo SINDICOBI, julho de 2005:3). ${ }^{12}$ O aumento da produtividade foi de 44\% (FIESP, 2006:17). O emprego cresceu $7 \%$ no período, a diminuição de custos foi de $5 \%$ e a arrecadação do ICMS aumentou em $170 \%$ nos últimos três anos, de acordo com o presidente do SINDICOBI. Segundo ele, os resultados do APL são evidentes:

De quatro anos para cá, nós começamos a ganhar mercado, nosso produto ganhou credibilidade, resgatou a nossa marca que é o bordado, porque até isso a gente estava

${ }^{12}$ A participação das empresas no APL compreende várias atividades: em primeiro lugar, há um acompanhamento da empresa por um consultor que a visita regularmente para registrar e discutir com a gerência problemas de produção, gargalos a serem atacados, melhorias possíveis. Há também um conjunto de cursos, visando o aperfeiçoamento gerencial, que abordam inúmeros aspectos ligados à melhoria da gestão da produção. Conforme palavras de um gerente que fez parte do primeiro grupo: "a primeira etapa foi bastante exaustiva. $\mathrm{O}$ ano de 2004 eu passei fazendo cursos; era de dia, de noite; era de todos os aspectos no meu segmento...". 
perdendo. Então a gente passou a ter de novo qualidade, desenvolvimento do produto e hoje as empresas estão mais estruturadas, passando a valorizar o aprendizado, com novas tecnologias e novos processos.

De fato, a opinião dos empresários consultados pela pesquisa foi muito favorável ao projeto. Na verdade, o APL Ibitinga foi considerado um dos melhores do estado de São Paulo, tendo sido escolhido pelo governo do estado para ser piloto na avaliação do BID - Banco Interamericano de Desenvolvimento, juntamente com o APL de Jaú, entre 35 experiências levadas a cabo no estado. Isso permitiu ao SINDICOBI pedir a implantação de um centro de formação e capacitação tecnológica ao BID, visando o atendimento às empresas e à comunidade no que se refere a qualificação e requalificação profissional, visando o incremento tecnológico do setor.

A experiência do APL veio somar ainda mais para o fortalecimento de um modelo de competitividade baseado na qualidade dos produtos e na qualificação da força de trabalho, o qual vem sendo reforçado por mais duas iniciativas importantes tomadas recentemente pelo empresariado. A primeira delas consiste na criação de uma Escola Técnica Estadual do Centro Paula Souza na cidade, com o objetivo de profissionalização da mão-de-obra voltada para o setor do bordado. A escola já está em funcionamento, com vários cursos operando. A segunda constitui o esforço que o SINDICOBI vem fazendo para responder à chamada pública do FINEP - Fundo Nacional de desenvolvimento de Estudos e Projetos, para a seleção de propostas de projetos de inovação e/ou difusão tecnológica de interesse de micro, pequenas e médias empresas (MPMEs). De acordo com o Informativo SINDICOBI, "a proposta visa selecionar o apoio financeiro a projetos a serem executados por instituições científicas $e$ tecnológicas em cooperação com as MPMEs, inseridas em Arranjos Produtivos Locais". O SINDICOBI conseguiu o apoio das universidades de São Carlos (USP e UFSCAR) para a elaboração 
As bordadeiras de Ibitinga: trabalho a domicílio e prática sindical

da proposta de desenvolvimento de um software inovador de inteligência competitiva para o setor de bordado.

Vale ressaltar ainda várias iniciativas de menor alcance tomadas pelo sindicato no sentido de qualificar a força de trabalho e desenvolver o marketing e o aprendizado tecnológico das empresas, entre as quais se destaca:

1) A preparação de vinte empresas do APL para participação na HEIMTEXTIL, a maior feira do setor cama, mesa $e$ banho do mundo, realizada em Frankfurt em janeiro de 2006. Essa missão foi um marco para as empresas do pólo, segundo o documento da FIESP,O arranjo produtivo de enxovais, bordados de cama, mesa e banho de Ibitinga (2006:20). A iniciativa vem se repetindo desde então.

2) O desenvolvimento do selo de procedência dos produtos produzidos pelo pólo de Ibitinga. Em parceria com o Parque Tecnológico de São Carlos, e com o SEBRAE subsidiando 80\% dos custos envolvidos para as empresas que participaram do projeto, o selo já foi criado.

\section{A categoria hoje}

A transformação do mercado de trabalho na indústria do bordado em Ibitinga nos últimos quinze anos é extremamente significativa. De uma categoria não regulamentada, que trabalhava na sua quase totalidade sem carteira assinada, espalhada em pequenas empresas, nos salões de bordado e no trabalho a domicílio, as trabalhadoras se transformaram em uma categoria organizada, que conquistou não só o reconhecimento da profissão pelo Ministério do Trabalho, como o direito de ser representada pelo sindicato e de ter a carteira assinada. $\mathrm{O}$ sindicato conseguiu também garantir um piso salarial bastante significativo quando comparado com outros municípios do estado.

$\mathrm{Na}$ realidade, o processo correspondeu a um imenso esforço sindical pela regulamentação da profissão, pela formalização do trabalho, pela melhoria das condições de trabalho e pela garantia 
das mesmas condições ao conjunto das trabalhadoras. A partir dele, o sindicato foi ganhando uma enorme confiança da base, evidenciada nos dias atuais por uma taxa de sindicalização de $70 \%$ da categoria.

Esse processo correspondeu também a uma formalização das empresas, que foram sendo forçadas a se organizar $e$ regulamentar sua situação, saindo da clandestinidade que caracterizava grande parte da produção do setor no início do período. Ele colaborou também para que as empresas fossem abandonando a estratégia de competitividade baseada na redução de custos para abraçar um caminho assentado na qualidade dos produtos e na qualificação da força de trabalho, visando o desenvolvimento tecnológico e a criação de parcerias, conforme atestam as iniciativas empresariais, sobretudo a partir de 2003, voltadas à qualificação dos trabalhadores e apoio às empresas. A mudança de estratégia foi também favorecida pela adoção de políticas de apoio à pequena e média empresa $e$ ao desenvolvimento econômico local, empreendidas pelo Governo Federal, a partir de iniciativas como a do FINEP, a do PROGEREN ${ }^{13}$ e de vários programas da Caixa Econômica Federal de apoio às pequenas e médias empresas.

Apesar dessa profunda mudança por que vem passando o mercado de trabalho da cidade, e de todo o esforço que o sindicato dos trabalhadores continua a desenvolver, é importante ressaltar que o trabalho a domicílio continua a ser realizado na cidade e que parte importante dele segue ainda sem registro em carteira. ${ }^{14}$

${ }^{13}$ Programa do BNDES que visa aumentar a produção, o emprego e a massa salarial, por meio de apoio financeiro, na forma de capital de giro para micros, pequenas e médias empresas localizadas em regiões contempladas por APLs.

${ }^{14} \mathrm{De}$ acordo com a tesoureira do sindicato, existe atualmente por volta de 8 mil trabalhadoras na categoria, das quais 6 mil possuem registro em carteira. As 2 mil restantes correspondem quase todas a trabalhadoras a domicílio, já que hoje em dia é muito difícil encontrar empresa que não registre suas trabalhadoras. Esse quadro favoreceu também uma diminuição significativa do trabalho infantil. 
As bordadeiras de Ibitinga: trabalho a domicílio e prática sindical

Entre os motivos apresentados pelas trabalhadoras a domicílio para continuar a bordar e costurar em casa, como já apontado em inúmeros outros estudos sobre o trabalho a domicílio no setor da confecção (Abramo, 1998; Leite, 2004; Amorim, 1999; Amorim, 2003; Amorim e Araújo, 2002; Araújo e Amorim, 2000; Abreu, 1986; Abreu e Sorj, 1994; Nunes Filho, 2002), encontram-se as relações sociais de gênero que responsabilizam as mulheres pelos cuidados domésticos, especialmente os relacionados à criação dos filhos. A lentidão da mudança nas relações de gênero no âmbito doméstico constitui, nesse sentido, um dos elementos centrais para a manutenção do trabalho a domicílio no município, especialmente quando se leva em conta a carência de mão-de-obra que o setor enfrenta atualmente e a facilidade que essas trabalhadoras teriam para se empregar em empresas regularizadas. Esse fato revela que, embora as mulheres venham conquistando maiores taxas de inserção no mercado de trabalho, diminuição na diferença salarial em relação ao rendimento masculino, maior permanência no mercado de trabalho mesmo com filhos pequenos, assim como acesso a postos de trabalho mais qualificados e mais altos na hierarquia das empresas (Bruschini e Lombardi, 2007), tais mudanças no comportamento e no imaginário sobre os papéis femininos $e$ masculinos são não só lentas, como ainda insuficientes para eliminar o trabalho feminino a domicílio, mesmo numa região onde elas não enfrentam dificuldades para encontrar trabalho nas empresas.

Vale destacar, entretanto, que a situação dessas mulheres hoje é bastante diferente daquela que viviam as bordadeiras no início da atividade, em que trabalhar a domicílio por conta própria podia ser mais vantajoso do que trabalhar em uma empresa. Ao que tudo indica, a desvalorização do trabalho a domicílio tem tudo a ver com a fraca procura atual desse tipo de trabalho.

Como hoje quase todo mundo é registrado, não tem mais como usar o trabalho infantil; o pouco que existe está restrito ao trabalho a domicilio. 
Marcia de Paula Leite

\section{Conclusão}

Ibitinga constitui um importante exemplo da capacidade de organização de uma categoria que conseguiu, durante um longo processo de lutas, modificar significativamente as condições de trabalho do setor do bordado e promover sua profissionalização, redesenhando assim as relações de trabalho daquela que viria a se constituir na principal atividade profissional da cidade. A partir de um processo que começou com a reunião de algumas bordadeiras para a formação da Associação Profissional, em 1987, seguida da criação do Sindicato dos Empregados, a categoria foi conseguindo não só a conquista de reivindicações que foram mudando profundamente suas condições de trabalho. Mais do que isso, ela conseguiu colaborar de maneira decisiva para o desenvolvimento industrial da cidade, na medida em que pressionava as empresas a se organizar e se legalizar, minando duramente a produção e o comércio clandestinos que caracterizavam a atividade do bordado naquele momento.

Nesse processo, o sindicato que buscou o apoio de muitas outras instituições - como as Centrais Sindicais, a Prefeitura Municipal, o Ministério do Trabalho e, inclusive em alguns momentos, o próprio sindicato patronal - acabou desempenhando um importante papel no sentido de colaborar para que as indústrias mudassem sua estratégia de competitividade baseada na extrema exploração da mão-de-obra para uma prática socialmente mais justa e economicamente mais viável de busca de qualidade de seus produtos e qualificação da força de trabalho.

Conforme alertado anteriormente, nesse caminhar o sindicato contou também com um importante apoio de políticas públicas, como a campanha pela carteira assinada desenvolvida pelo Ministério do Trabalho, durante a gestão do ministro Walter Barelli, assim como as medidas que tomou buscando tornar mais produtiva e eficaz a fiscalização pelo cumprimento da legislação trabalhista e dos acordos assinados em convenção coletiva. 
As bordadeiras de Ibitinga: trabalho a domicílio e prática sindical

Destaque-se, também, a adoção de políticas de apoio à pequena e média empresa e ao desenvolvimento econômico local, empreendidas pelo atual governo federal, as quais vêm contando também com um importante apoio de instituições empresariais como o Sebrae e a FIESP, bem como do governo estadual.

Pode-se afirmar, assim, que o desenvolvimento vivido por Ibitinga nos últimos anos foi fruto de uma feliz coincidência entre uma prática sindical combativa e responsável empunhada pelas trabalhadoras do bordado, a partir de seu sindicato, e de um conjunto de políticas públicas que passou a favorecer tais lutas, colaborando para que o empresariado fosse mudando sua estratégia e o perfil industrial da cidade. Esse processo teve um importante impulso com a promoção do APL Ibitinga. A partir daí, a ação do empresariado tornou-se também mais efetiva, configurando uma situação que pode ser considerada como uma concertação social a nível territorial.

É importante sublinhar, entretanto, conforme alertado anteriormente, que esse conjunto de mudanças não foi suficiente para eliminar o trabalho feminino a domicílio; embora bastante reduzido, ele traz ainda à luz a manutenção do imaginário patriarcal que confere às mulheres a responsabilidade pelo trabalho doméstico. É ele que está por trás da preferência de um conjunto de mulheres, ainda que pouco expressivo, pelo trabalho a domicílio na região.

Finalmente, vale lembrar que, frente ao processo mais geral de enfraquecimento dos sindicatos e aumento do trabalho sem registro em carteira verificado nas últimas décadas (sobretudo na dos anos 1990), a experiência do Sindicato das Bordadeiras de Ibitinga emerge como um contra exemplo de grande relevância. Embora não se possa esquecer das condições específicas do município, especialmente no que se refere à escassez de mão-deobra face às necessidades das empresas, não há dúvida de que essa experiência irrompe como um alento de que nem tudo são perdas para o movimento sindical e de que novos caminhos $e$ estratégias podem ter efeitos inesperados. 
Marcia de Paula Leite

\section{Referências bibliográficas:}

ABRAMO, Laís. Um olhar de gênero: visibilizando a precarização ao longo das cadeias produtivas. In: ABRAMO, Laís e ABREU, Alice. (orgs.) Gênero e trabalho na sociologia Latino-Americana. São Paulo/Rio de Janeiro, ALAST, 1998, pp.39-61.

. A inserção da mulher no mercado de trabalho: Uma força de trabalho secundária? Tese de doutorado, São Paulo, Sociologia, USP, 2007.

ABREU, Alice. O avesso da moda: trabalho a domicílio na indústria de confecção. São Paulo, Hucitec, 1986.

e SORJ, Bila. Subcontratação e relações de gênero na indústria de confecção. In: ABREU, Alice e PESSANHA, Elina. (orgs.) $O$ trabalhador carioca: estudos sobre trabalhadores urbanos no Rio de Janeiro. Rio de Janeiro, JC Editora, 1994, pp.139-153.

AMORIM, Elaine. O trabalho feminino no novo paradigma produtivo: uma análise das trabalhadoras das indústrias têxteis e do vestuário de Campinas e Americana. Relatório de Pesquisa, Fapesp, 1999.

- No limite da precarização? Terceirização e trabalho feminino na indústria de confecção. Dissertação de Mestrado, Campinas-SP, Instituto de Filosofia e Ciências Humanas, Unicamp, 2003.

e ARAÚso, Ângela. Redes de subcontratação e trabalho a domicílio na indústria de confecção: um estudo na região de Campinas. Cadernos Pagu (17-18), Campinas-SP, Núcleo de Estudos de Gênero - Pagu/Unicamp, 2002, pp.267-310.

ARAÚJO, Ângela. Os sentidos do trabalho da mulher no contexto da reestruturação produtiva. XV International Congress on Women's Health Issues. São Pedro-SP, 7 a 11 de novembro de 2004.

e AMORIM, Elaine. Redes de subcontratação e trabalho a domić́lio na indústria de confecção: um estudo na região de Campinas. XXIV Encontro Anual da ANPOCS, Caxambu-MG, 2000.

BRUSCHINI, Cristina e LOMBARDI, Maria Rosa. Trabalho e gênero no Brasil nos últimos dez anos. Seminário Internacional Gênero e Trabalho, São Paulo e Rio de Janeiro, 8 a 12 de abril de 2007. 
As bordadeiras de Ibitinga: trabalho a domicílio e prática sindical

BUFELLI et alii. A atuação das relações públicas modificando a realidade trabalhista e social de uma categoria profissional. Trabalho de Conclusão de Curso, Departamento de Comunicação Social, Universidade de Bauru, 1987.

FIESP. O arranjo produtivo de enxovais bordados de cama, mesa e banho de Ibitinga, junho de 2006.

LEITE, Marcia. Tecendo a precarização: Trabalho a domicílio e estratégias sindicais na indústria de confecção em São Paulo. Revista Trabalho, Educação e Saúde vol. 2 (1), março de 2004, pp.57-93.

MARUANI, Margaret e HIRATA, Helena. As novas fronteiras da desigualdade. Homens e mulheres no mercado de trabalho, São Paulo, Editora Senac, 2003.

NUNES Filho, Geraldo. Vida, trabalho e saúde: costureiras a domicílio. Tese de Doutorado, São Paulo, Faculdade de Saúde Pública/USP, 2002.

SAWAIA, Bader. Ibitinga - suas práticas e representações sociais. Dissertação de mestrado, São Paulo, PUC, 1979. 